\title{
Anterior Segment OCT
}

\author{
Jacqueline Sousa Asam, Melanie Polzer, \\ Ali Tafreshi, Nino Hirnschall, and Oliver Findl
}

\subsection{Introduction}

OCT technology was initially introduced to the ophthalmic field for imaging of the posterior segment such as the retina and the optic nerve head. However, advancements to the technology made it possible for image acquisition of the ocular surface and anterior segment. Imaging of these anatomical structures has shown to be of significant clinical relevance. Anterior segment OCT imaging allows for visualization and assessment of anterior segment ocular features, such as the tear film, cornea, conjunctiva, sclera, rectus muscles, anterior chamber angle structures, and lens [1].

The first commercial OCT systems specifically designed for anterior segment imaging were the Zeiss Visante OCT ${ }^{\mathrm{TM}}$ (Carl Zeiss Meditec, Dublin, CA, USA) and the Slit-Lamp OCT (SL-OCT, Heidelberg Engineering GmbH, Heidelberg, Germany). Both of these devices received clearance by the United States Food and Drug Administration (FDA) in 2005 and 2006, respectively. These time-domain OCT devices

\footnotetext{
J. S. Asam · M. Polzer · A. Tafreshi $(\bowtie)$

Heidelberg Engineering $\mathrm{GmbH}$,

Heidelberg, Germany

N. Hirnschall · O. Findl

Vienna Institute for Research in Ocular Surgery

(VIROS), Hanusch Hospital, Vienna, Austria
}

employed longer wavelength light sources (both Visante OCT $^{\text {TM }}$ and SL-OCT: $1310 \mathrm{~nm}$ ) and provided images with relatively high axial ranges and penetration but at the cost of axial resolution (between 18 and $25 \mu \mathrm{m}$ ) and scan speed (2000 A-scans/second with the Visante OCT system, and $200 \mathrm{~A}-$-scans/second with the SL-OCT) [2]. With the commercial introduction of spectraldomain OCT (SD-OCT) technology, imaging of the anterior segment at much higher speeds (> 25,000 A-scans/second) and better axial resolution became a possibility [2]. However, these commercial SD-OCT devices use shorter wavelength light sources $(820-880 \mathrm{~nm})$, optimized for posterior segment imaging, resulting in a more limited image depth range and potentially lower penetration of deeper structures.

Swept-source OCT (SS-OCT) technology combined with a longer wavelength light source offers inherent characteristics that are suitable for anterior segment imaging and analyses. While a longer wavelength light source allows for imaging along a large image depth, the SS-OCT technique allows for minimal sensitivity roll-off along this depth. This combination and the very short acquisition time allow for high-contrast images of the entire anterior chamber, until the posterior surface of the lens $[1,2]$. The images provide visualization and analytics of clinically relevant anterior segment structures of the human eye on one device. 
These structures include the cornea, anterior chamber, iris, and lens. A long wavelength light source combined with SS-OCT technology can also serve as a tool to measure the axial length of the human eye. The above-mentioned structures and parameters are widely used in ophthalmology for assessment of clinically relevant parameters such as corneal topography, corneal tomography, anterior segment analysis, biometry and calculation of intraocular lens power.

\subsection{Anterior Segment Spectral- Domain OCT (SD-OCT)}

The SPECTRALIS Anterior Segment Module (ASM) is an add-on lens, accompanied by a software package that can be added to the SPECTRALIS SD-OCT device. The ASM offers high-resolution cornea, sclera and anterior chamber angle images.

The lateral scan range varies from 8 to $16 \mathrm{~mm}$ with two different scan patterns: single and raster. There are predefined scan patterns depending on the application (cornea, anterior chamber angle, and sclera) (Table 13.1). The Heidelberg Noise Reduction and the TruTrack Active Eye Tracking allow for enhanced detailed images and precise alignment, respectively. The software also provides an interactive zoom function, which can be positioned during live image acquisition, on the area of interest.

The layers of the cornea can be seen in detail with the SPECTRALIS ASM, aiding in the assessment of corneal thickness (Fig. 13.1).
These high-resolution images add clinically relevant information for the detection and management of various corneal abnormalities including, but not limited to, corneal opacities, corneal scars, and corneal dystrophies. Such images are also useful in the planning or post-surgical evaluation of penetrating and lamellar keratoplasties, and refractive surgeries (Fig. 13.2). It has been shown that ultra-high-resolution OCT

Table 13.1 SPECTRALIS ASM Module, Heidelberg Engineering

\begin{tabular}{|c|c|c|c|}
\hline & $\begin{array}{l}\text { OCT scan } \\
\text { size }\end{array}$ & $\begin{array}{l}\text { cSLO } \\
\text { image }\end{array}$ & $\begin{array}{l}\text { Number of } \\
\text { sections }\end{array}$ \\
\hline \multicolumn{4}{|c|}{ Cornea application } \\
\hline Single detail & $8 \mathrm{~mm}$ & $11 \mathrm{~mm}$ & 1 \\
\hline $\begin{array}{l}\text { Single } \\
\text { overview }\end{array}$ & $11 \mathrm{~mm}$ & $16 \mathrm{~mm}$ & 1 \\
\hline Volume small & $8 \times 2.8 \mathrm{~mm}$ & $11 \mathrm{~mm}$ & 11 \\
\hline Volume large & $8 \times 5.6 \mathrm{~mm}$ & $11 \mathrm{~mm}$ & 21 \\
\hline Volume detail & $8 \times 1.7 \mathrm{~mm}$ & $11 \mathrm{~mm}$ & 25 \\
\hline \multicolumn{4}{|c|}{ Chamber angle application } \\
\hline $\begin{array}{l}\text { Single one } \\
\text { angle }\end{array}$ & $8 \mathrm{~mm}$ & $11 \mathrm{~mm}$ & 1 \\
\hline $\begin{array}{l}\text { Single both } \\
\text { angles }\end{array}$ & $16 \mathrm{~mm}$ & $16 \mathrm{~mm}$ & 1 \\
\hline Volume small & $8 \times 2.8 \mathrm{~mm}$ & $11 \mathrm{~mm}$ & 11 \\
\hline \multicolumn{4}{|c|}{ Sclera application } \\
\hline Single detail & $8 \mathrm{~mm}$ & $11 \mathrm{~mm}$ & 1 \\
\hline $\begin{array}{l}\text { Single } \\
\text { overview }\end{array}$ & $11 \mathrm{~mm}$ & $16 \mathrm{~mm}$ & 1 \\
\hline Volume small & $8 \times 2.8 \mathrm{~mm}$ & $11 \mathrm{~mm}$ & 11 \\
\hline Volume large & $8 \times 5.6 \mathrm{~mm}$ & $11 \mathrm{~mm}$ & 21 \\
\hline Volume detail & $8 \times 7.1 \mathrm{~mm}$ & $11 \mathrm{~mm}$ & 25 \\
\hline $\begin{array}{l}\text { Volume } \\
\text { filtering blebs }\end{array}$ & $8 \times 2.8 \mathrm{~mm}$ & $16 \mathrm{~mm}$ & $\begin{array}{l}21 \text { (vertical } \\
\text { scan) }\end{array}$ \\
\hline
\end{tabular}

$O C T$ optical coherence tomography, $c S L O$ confocal scanning laser ophthalmoscope

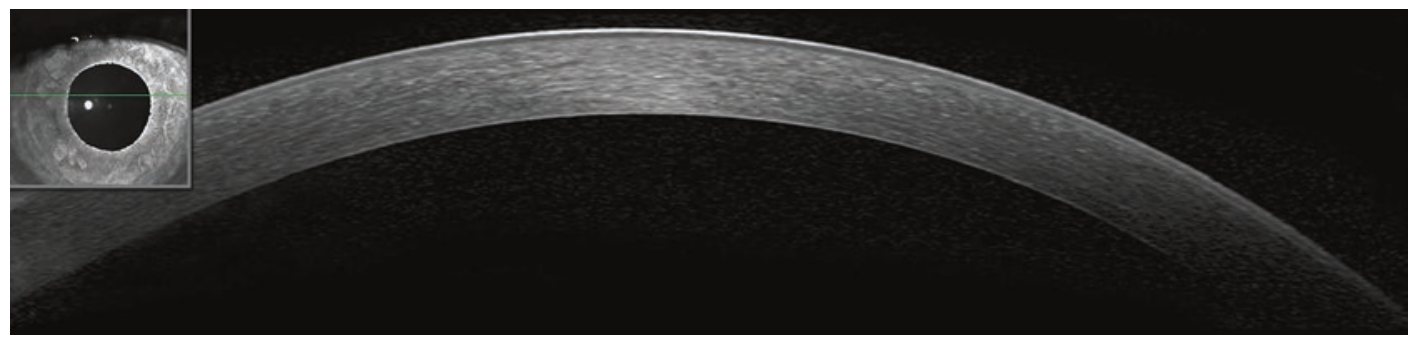

Fig. 13.1 SPECTRALIS ASM. Healthy cornea 


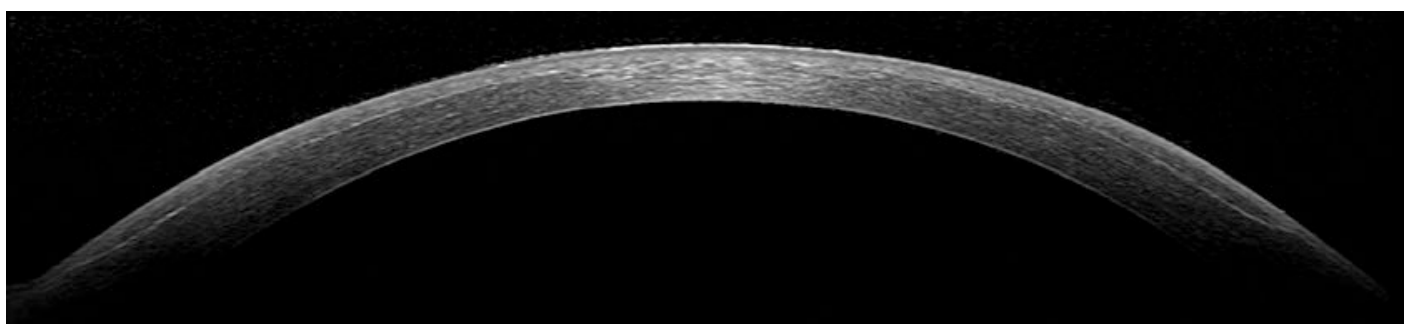

Fig. 13.2 SPECTRALIS ASM. Cornea after refractive surgery, showing the LASIK flap

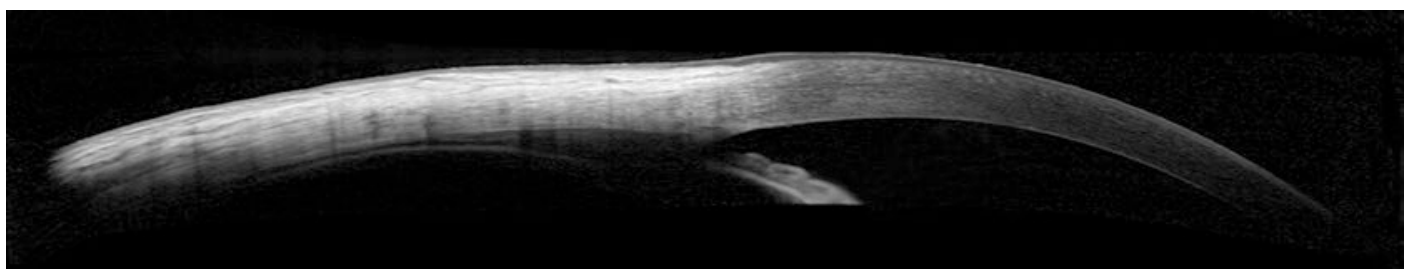

Fig. 13.3 SPECTRALIS ASM. Sclera, anterior chamber angle and cornea of a healthy patient

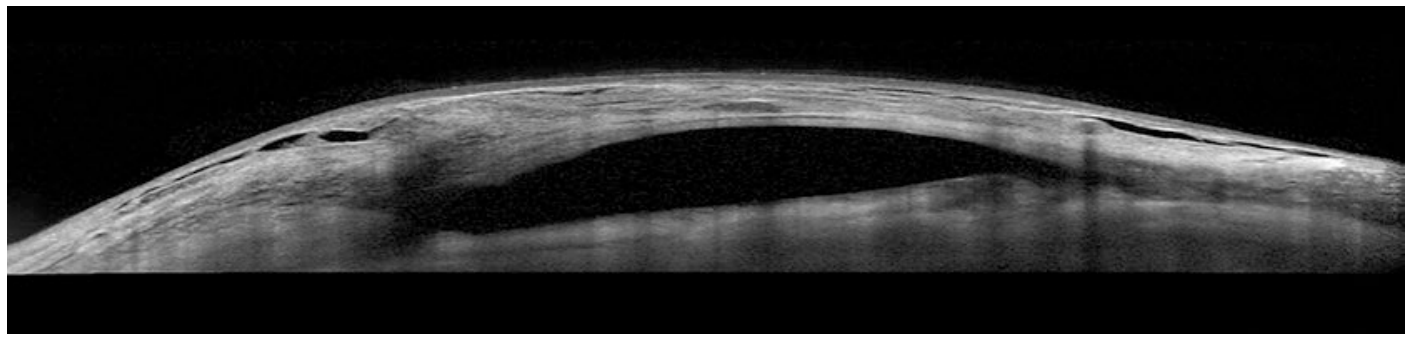

Fig. 13.4 SPECTRALIS ASM. Sclera after trabeculoplasty, showing the filtering bleb

(spectral-domain) images are able to detect Acanthamoeba disease in the cornea, aiding the diagnosis of this rare keratitis in a non-contact and patient-friendly manner [3, 4]. Another application is the visualization and quantification of corneal haze after cross-linking, which can be compared to the normal healing process [5]. Cytomegalovirus associated keratitis can also be imaged with OCT technology, presenting with a dendritic, dome-shaped, quadrangular, or saw-tooth appearance as well as a coin-shaped structure [6].

Images of the scleral anatomy may be clinically useful in the diagnosis and management of some diseases such as scleral and conjunctiva neoplasia, and inflammation. Surgical procedures affecting the scleral structure, such as a filtering bleb post glaucoma surgery, may also be evaluated for functional efficacy with high-resolution images (Figs. 13.3 and 13.4).

The $16 \mathrm{~mm}$ white-to-white scan offers an image where two anterior chamber angles across a single OCT B-Scan can be seen, facilitating anterior chamber angle assessment. In addition, manual measurement tools can be used to measure the cornea, sclera and chamber angle structures. Both ACA (anterior chamber angle) and AOD (angle opening distance) measurements are available, adding clinically relevant information for the assessment of narrow or closed angles (Fig. 13.5). These measurement tools are not 510(k) FDA cleared. 


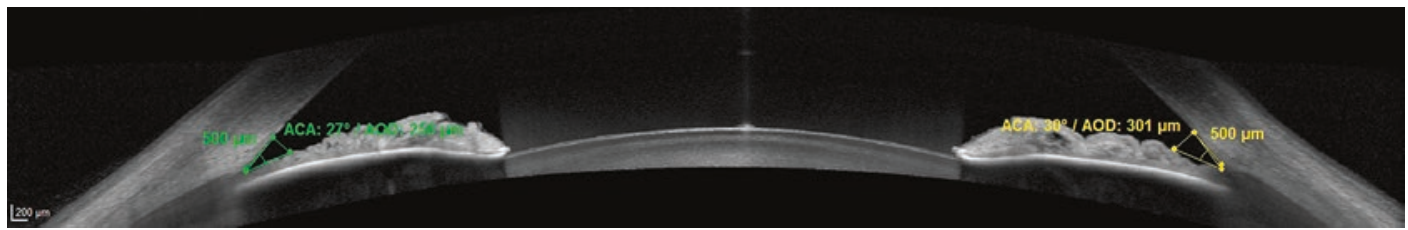

Fig. 13.5 SPECTRALIS ASM, anterior chamber angle measuring tools. ACA (anterior chamber angle) and AOD (angle opening distance) of a healthy patient

\subsection{Anterior Segment Swept Source OCT (SS-OCT)}

ANTERION utilizes high-resolution SS-OCT images to combine corneal examination, eye and anterior segment biometry, IOL (intraocular lens) calculation and anterior segment imaging via four different applications: Cornea App, Cataract App, Metrics App and Imaging App. The SS-OCT technology at $1300 \mathrm{~nm}$ delivers high-resolution images of the anterior segment along a large image depth, at a fast acquisition speed. The detailed images of the anterior surface of the cornea to the posterior surface of the lens and the anterior chamber angle allow for reliable measurements needed in planning of anterior segment surgeries, such as cataract surgery, refractive surgery and keratoplasty. In addition, the high quality images serve as a diagnostic aid for various anterior segment abnormalities. Table 13.2 summarizes the measurement parameters and features while Table 13.3 indicates the technical specifications of each ANTERION app.

\subsubsection{SS-OCT and Cornea Evaluation}

Fast acquisition of images using the SS-OCT technology allows for high-resolution imaging with reliable resultant measurements. A total of 65 radial B-Scan images (256 A-scans per B-Scan) are acquired in less than one second using the ANTERION Cornea App. All corneal maps are $8 \mathrm{~mm}$ in diameter and are generated from SS-OCT image data. These maps include: anterior and posterior axial curvature, tangential curvature and elevation maps, as well as total corneal power map, anterior and total corneal wavefront and pachymetry maps (Fig. 13.6). In addition, a detailed wavefront parameter analysis with aberration quantification is demonstrated for both anterior and total corneal wavefront. It has been shown that SS-OCT pachymetry results are more repeatable than Scheimpflug imaging results, in healthy corneas [7]. Furthermore, SS-OCT has been shown to have higher reliability and repeatability than high-resolution Scheimpflug imaging in patients who have undergone corneal grafting [8].

The corneal asymmetry maps and parameters may be used to detect abnormalities that present asymmetrically, e.g., in early corneal ectasia (Fig. 13.7). In addition, corneal maps and parameters can be shown as a series of follow-up examinations, facilitating the ability to identify changes over time, for example after surgical procedures and orthokeratology (Fig. 13.8).

OCT measurements and Scheimpflug imaging are the gold standard for keratoconus diagnostics (Fig. 13.9) [9]. The SS-OCT measurement techniques have been shown to detect keratoconus in early stages, with improved accuracy compared to other methods [10].

Evaluation of corneal surgical interventions with SS-OCT covers a large variety of techniques, such as refractive surgery, keratoplasty, intrastromal corneal rings and others (Fig. 13.10) [1, 11, 12]. In general, SS-OCT measurements have been shown to have better repeatability of corneal biometrical measurements compared with Scheimpflug, for corneal graft evaluation [8]. Due to this advantage, SS-OCT imaging is being routinely accepted as the method of choice for such measurements, gradually replacing other imaging techniques. High-resolution OCT images also allow for a detailed analysis of the post-operative morphology of the cornea, including comparison 
Table 13.2 ANTERION parameters and features per application

\begin{tabular}{|c|c|c|c|c|}
\hline \multicolumn{5}{|c|}{ ANTERION, Heidelberg Engineering } \\
\hline & Cornea App & Cataract App & Metrics App & Imaging App \\
\hline Parameters & $\begin{array}{l}\text { - OCT image } \\
\text { - IR camera image } \\
\text { - Anterior and posterior } \\
\text { axial curvature maps } \\
\text { - Anterior and posterior } \\
\text { tangential curvature } \\
\text { maps } \\
\text { - Anterior and posterior } \\
\text { elevation maps } \\
\text { - Total corneal power map } \\
\text { - Anterior and total } \\
\text { corneal wavefront maps } \\
\text { and analysis } \\
\text { - Pachymetry map } \\
\text { - Pupil diameter } \\
\text { - Kappa angle } \\
\text { - White-to-white } \\
\text { - Corneal vertex } \\
\text { - Thinnest point } \\
\text { - Minimum radius }\end{array}$ & $\begin{array}{l}\text { - OCT image } \\
\text { - IR camera image } \\
\text { - Total corneal power } \\
\text { map and parameters } \\
\text { - Anterior axial } \\
\text { curvature map and } \\
\text { parameters } \\
\text { - Total corneal } \\
\text { wavefront } \\
\text { - Central corneal } \\
\text { thickness } \\
\text { - Axial length } \\
\text { - Aqueous depth } \\
\text { - Lens thickness } \\
\text { - Pupil diameter and } \\
\text { kappa angle } \\
\text { - White-to-white } \\
\text { - Spheric IOL } \\
\text { calculator } \\
\text { - Toric IOL calculator }\end{array}$ & $\begin{array}{l}\text { - } \text { OCT image } \\
\text { - IR camera image } \\
\text { - ACA 500/750 } \\
\text { - SSA 500/750 } \\
\text { - AOD 500/750 } \\
\text { - TISA 500/750 } \\
\text { - Lens thickness } \\
\text { - Lens vault } \\
\text { - Aqueous depth and } \\
\text { anterior chamber } \\
\text { volume } \\
\text { - Angle-to-angle } \\
\text { distance } \\
\text { - Spur-to-spur distance } \\
\text { - Central corneal } \\
\text { thickness } \\
\text { - White-to-white } \\
\text { - Pupil diameter and } \\
\text { kappa angle } \\
\text { - Free measurements }\end{array}$ & $\begin{array}{l}\text { - OCT image } \\
\text { - IR camera image }\end{array}$ \\
\hline Features & $\begin{array}{l}\text { - } 4 \text { segments and zones } \\
\text { information } \\
\text { - Both eyes layout with } \\
\text { differential maps and } \\
\text { parameters } \\
\text { - Follow-up layout with } \\
\text { differential maps and } \\
\text { parameters } \\
\text { - Progression analysis } \\
\text { - Multiview layout }\end{array}$ & $\begin{array}{l}\text { - Cornea App } \\
\text { information can be } \\
\text { integrated } \\
\text { - Cornea and lens } \\
\text { OCT intensity graph } \\
\text { - Both eyes differential } \\
\text { parameters }\end{array}$ & $\begin{array}{l}\text { - } 360^{\circ} \text { angle } \\
\text { parameters graphs } \\
\text { - Multiview layout }\end{array}$ & $\begin{array}{l}\text { Personalized } \\
\text { scan pattern, } \\
\text { size, density, } \\
\text { resolution and } \\
\text { location }\end{array}$ \\
\hline
\end{tabular}

OCT optical coherence tomography, IR infrared, IOL intraocular lens, ACA anterior chamber angle, SSA scleral spur angle, $A O D$ angle opening distance, TISA trabecular-iris space area

Table 13.3 ANTERION technical specifications per application

\begin{tabular}{|c|c|c|c|c|c|c|}
\hline \multicolumn{7}{|c|}{ ANTERION, Heidelberg Engineering } \\
\hline \multirow[b]{2}{*}{$\begin{array}{l}\text { Technical } \\
\text { specifications }\end{array}$} & \multirow[b]{2}{*}{ Cornea App } & \multicolumn{3}{|l|}{ Cataract App } & \multirow[b]{2}{*}{ Metrics App } & \multirow[b]{2}{*}{ Imaging App } \\
\hline & & Cornea & AS biometry & $\begin{array}{l}\text { Axial } \\
\text { length }\end{array}$ & & \\
\hline $\begin{array}{l}\text { Resolution (in } \\
\text { tissue) }(\mu \mathrm{m})\end{array}$ & $\begin{array}{l}<10 \\
\text { axially } \times<45 \\
\text { laterally }\end{array}$ & $\begin{array}{l}<10 \\
\text { axially } \times<45 \\
\text { laterally }\end{array}$ & $\begin{array}{l}<10 \text { axially } \times 30 \\
\text { laterally }\end{array}$ & NA & $\begin{array}{l}<10 \text { axially } \times 30 \\
\text { laterally }\end{array}$ & $\begin{array}{l}<10 \text { axially } \times 30 \\
\text { laterally }\end{array}$ \\
\hline $\begin{array}{l}\text { Image size (in } \\
\text { air) }(\mathrm{mm})\end{array}$ & $\begin{array}{l}11 \pm 1 \\
\text { axially } \times 9 \\
\text { laterally }\end{array}$ & $\begin{array}{l}11 \pm 1 \\
\text { axially } \times 9 \\
\text { laterally }\end{array}$ & $\begin{array}{l}14 \pm 0.5 \\
\text { axially } \times 16.5 \\
\text { laterally }\end{array}$ & NA & $\begin{array}{l}14 \pm 0.5 \\
\text { axially } \times 16.5 \\
\text { laterally }\end{array}$ & $\begin{array}{l}14 \pm 0.5 \\
\text { axially } \times 16.5 \\
\text { laterally }\end{array}$ \\
\hline Scan pattern & Radial & Radial & Line & NA & Radial & $\begin{array}{l}\text { Linear, volume, } \\
\text { arc and radial }\end{array}$ \\
\hline $\begin{array}{l}\text { Number of } \\
\text { B-Scans }\end{array}$ & 65 & 65 & 1 (averaged) & NA & 6 (averaged) & Personalized \\
\hline $\begin{array}{l}\text { Number of } \\
\text { A-scans per } \\
\text { B-Scan }\end{array}$ & 256 & 256 & 768 & NA & 768 & Personalized \\
\hline $\begin{array}{l}\text { Axial length } \\
\text { range }(\mathrm{mm})\end{array}$ & NA & NA & NA & $\begin{array}{l}14- \\
32\end{array}$ & NA & NA \\
\hline
\end{tabular}

$A S$ anterior segment, $N A$ not applicable 


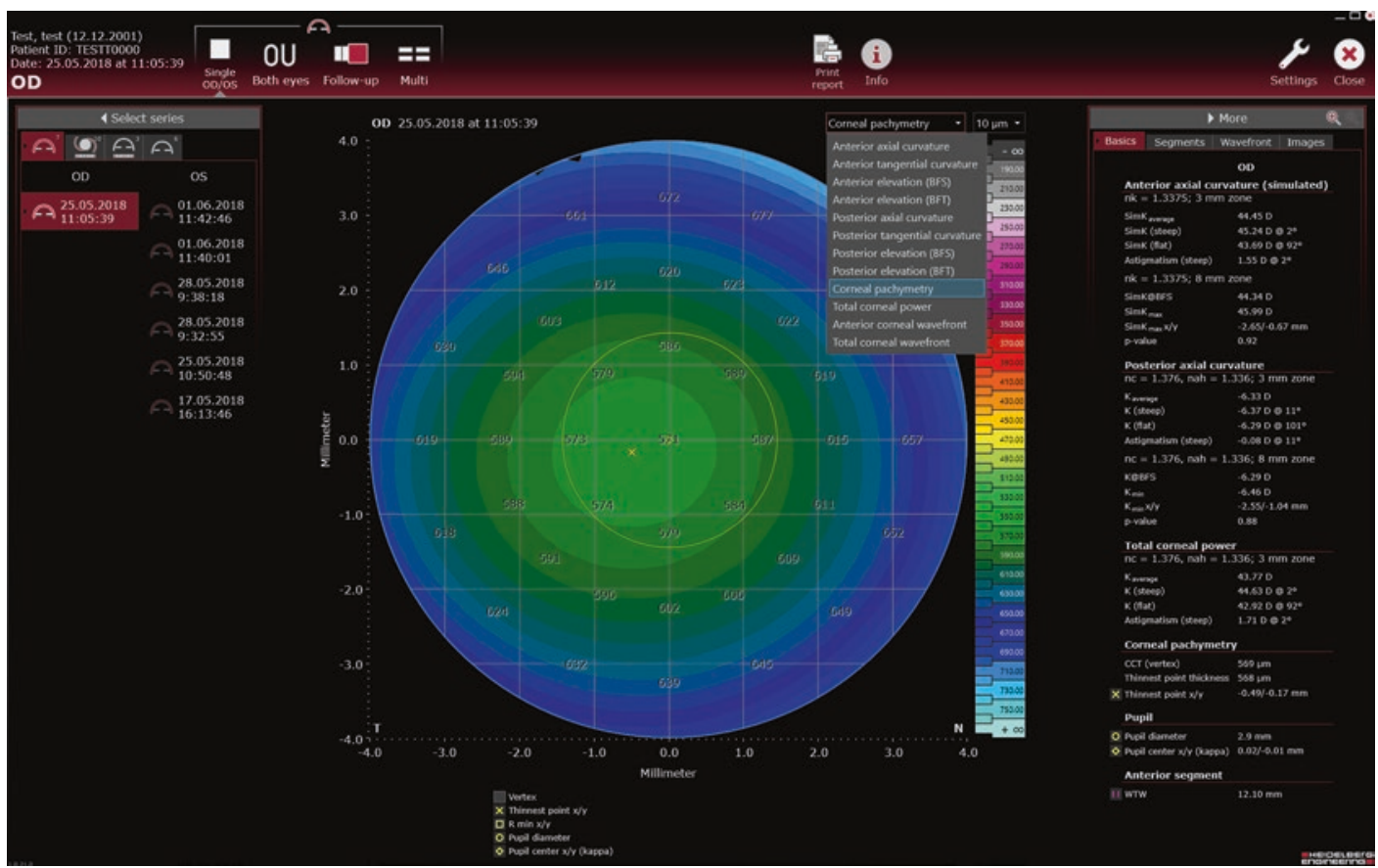

Fig. 13.6 ANTERION Cornea App single view. Pachymetry map, map options and corneal parameters of a healthy eye

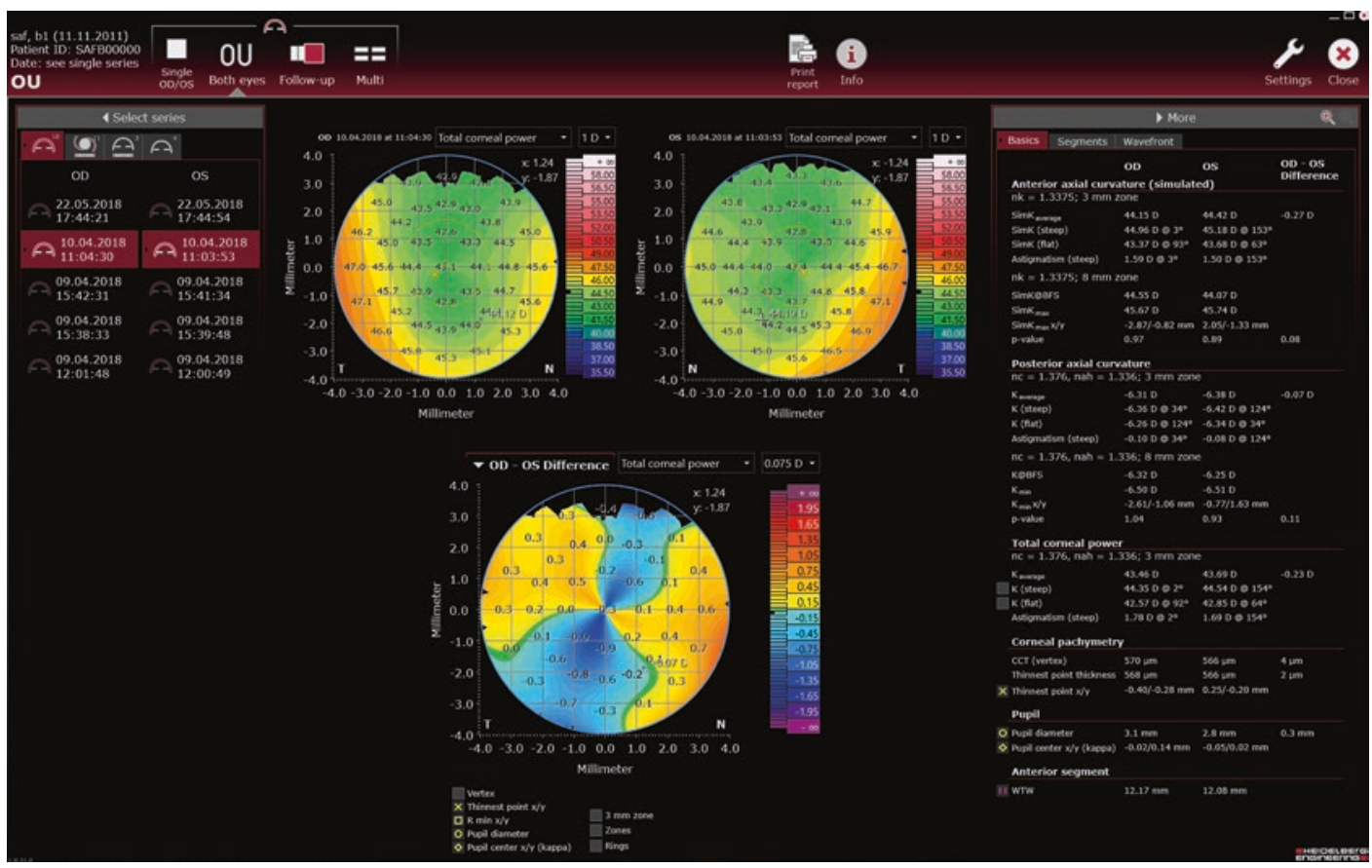

Fig. 13.7 ANTERION Cornea App both eyes (OU) view. Total corneal power maps of both eyes, differential map (center below) and parameters (table on the right) of a healthy patient 


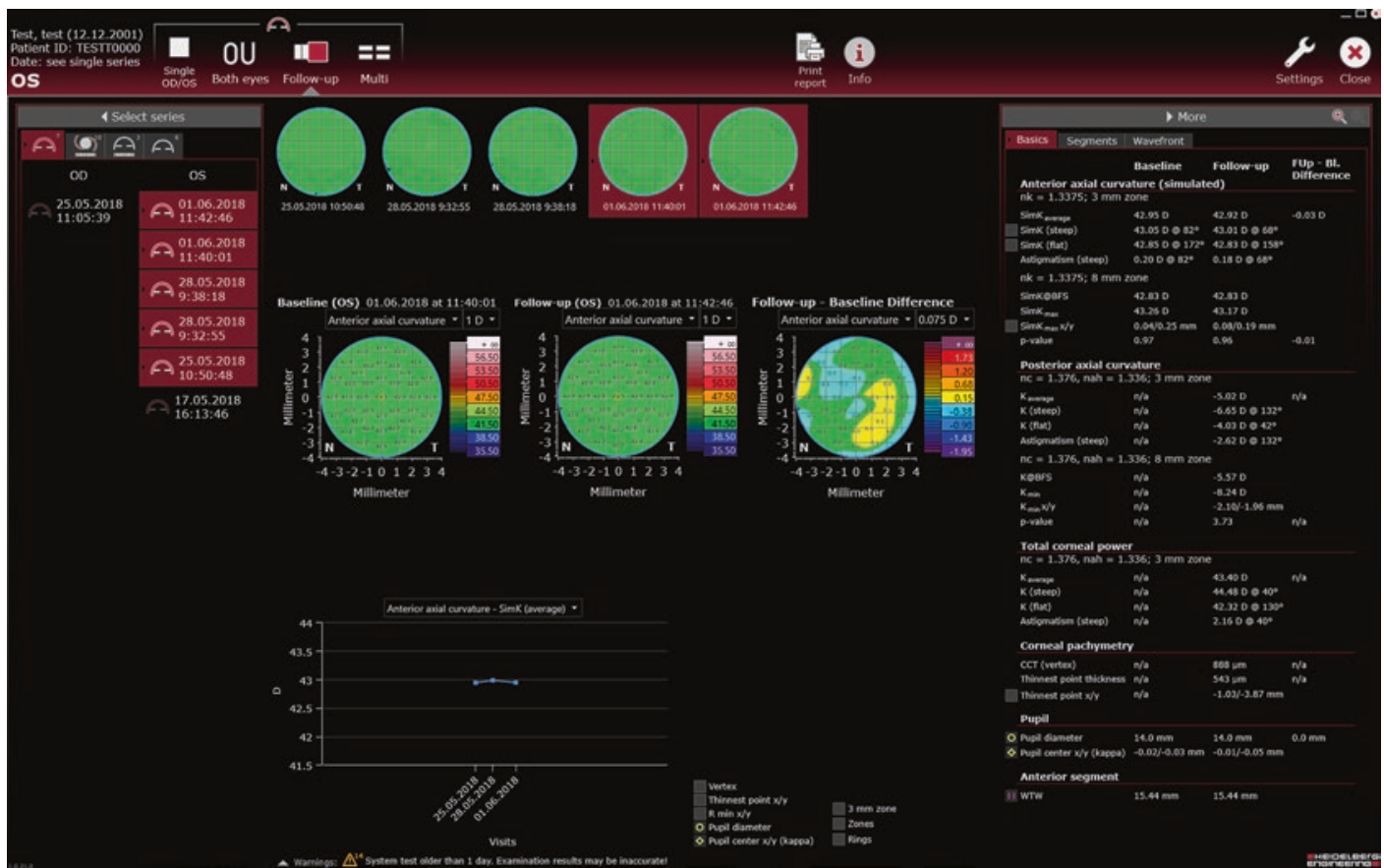

Fig. 13.8 ANTERION Cornea App follow-up view. Anterior axial curvature maps of the same eye with differential map and progression analysis of a healthy patient

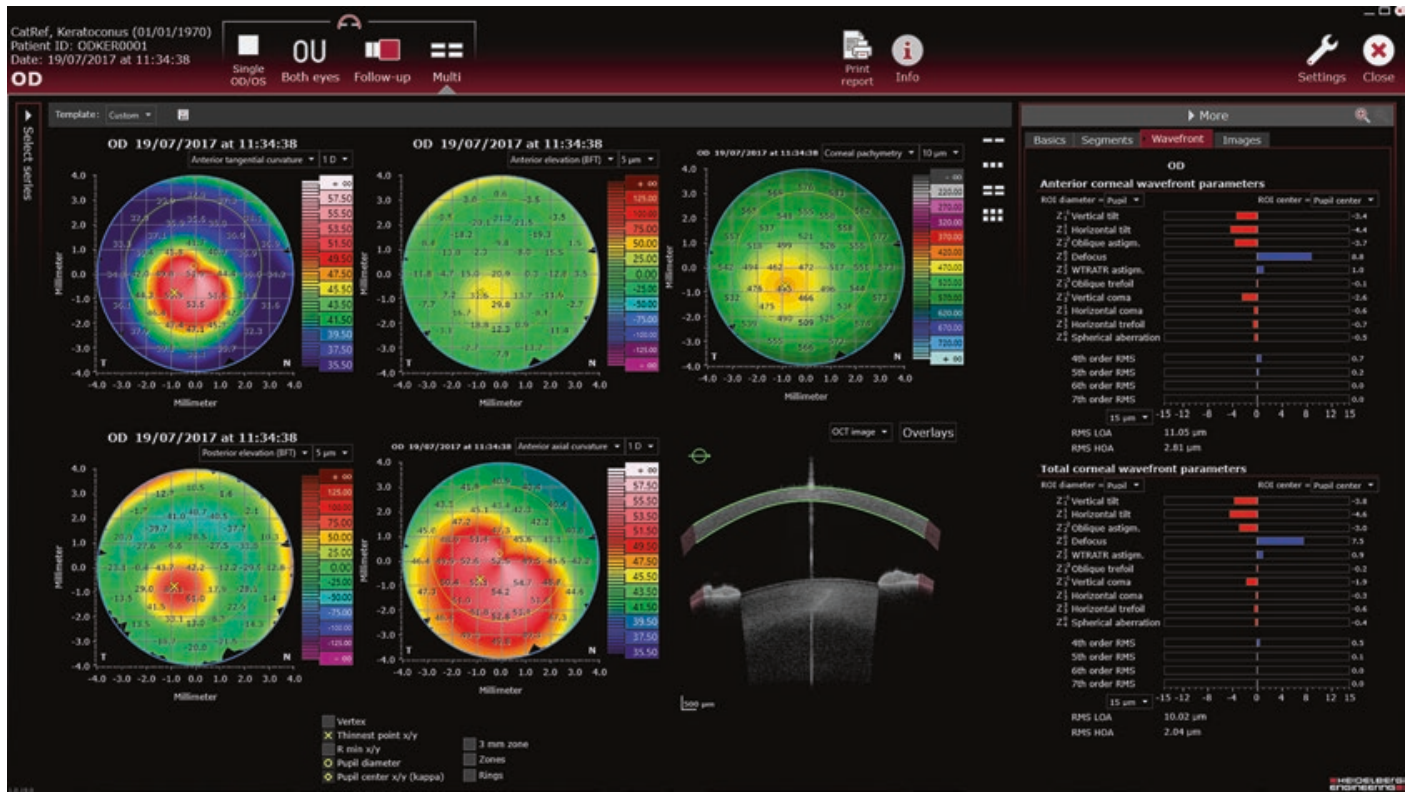

Fig. 13.9 ANTERION Cornea App multiview. Five corneal maps (anterior tangential curvature, anterior elevation, corneal pachymetry, posterior elevation and anterior axial curvature), OCT image and wavefront parameters of a keratoconus eye 
Fig.13.10 ANTERION Imaging App. Intrastromal corneal ring in a keratoconus eye

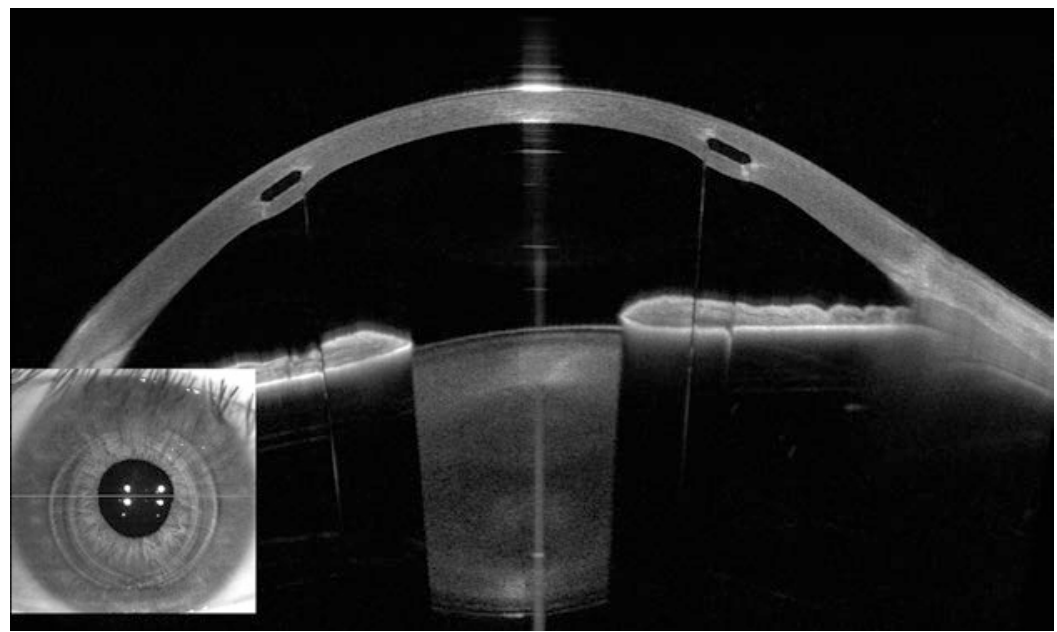

between follow-ups. Furthermore, the demarcation line seen after cross-linking can be detected using SS-OCT technology, but not with the slit lamp exam [13].

Evaluation of the tear film is another possible application of SS-OCT on the cornea. Fukuda et al. [14] and Akiyama et al. [15] showed significant correlations between the tear film meniscus and vital staining scores and Schirmer test results. In a more recent study, the effect of different dry eye treatment options was also evaluated using SS-OCT. [16] Therefore, SS-OCT technology is a potentially useful method to document tear film abnormalities as well as being able to monitor treatment.

OCT measurements have also been shown to allow for distinction of bacterial, viral and fungal keratitis from retrocorneal plaques. In cases with bacterial and viral keratitis, there is a distinct boundary between the corneal endothelial surface and the plaque. This boundary is more diffuse in cases with fungal keratitis [17]. In the case of mild to moderate corneal scaring due to keratitis or other causes, visual quality is often severely decreased. Recently, it was found that the decrease in visual acuity in these patients is not only caused by the cornea opacification itself, but also due to the increased higher-order aberrations generated by an irregular corneal surface, which may be treated with rigid gas-permeable lenses $[18,19]$. SS-OCT measurements may be used to detect corneal irregularities in the future and to help in the decision making process of determining whether contact lenses are sufficient or if surgical intervention is necessary.

Novel full-field and ultra-high-resolution OCT devices have recently evaluated human corneas, and showed the possibility to image even nuclei of the corneal endothelium [20]. Another novel application is the use of OCT angiography for evaluating and quantifying corneal vascularization. Several studies have shown that this measurement technique is equivalent to conventional angiography [21-23].

\subsubsection{SS-OCT and Cataract Evaluation}

Some anterior segment SS-OCT devices provide the visualization of the whole crystalline lens (Fig. 13.11), showing utility for cataract quantification and density documentation [24]. Furthermore, lens measurements using this technology have been shown to be highly reproducible [25]. Until now, not all types of cataracts can be detected and measured with equal accuracy. Quantifying and documenting cataracts with SS-OCT could be useful in identifying eyes with good visual acuity, but symptomatic of having haziness, glare and haloes. These eyes may benefit from cataract surgery. This is especially the case for anterior cortical cataract cases, which often allow for good visual acuity but have significantly increased stray light levels. 
One of the most significant applications of SS-OCT technology is optical biometry. SS-OCT with a wavelength of $1055 \mathrm{~nm}$ allowed for axial length measurements with a significantly better penetration through dense cataracts compared to conventional optical biometry techniques [26]. The SS-OCT ANTERION with a wave-

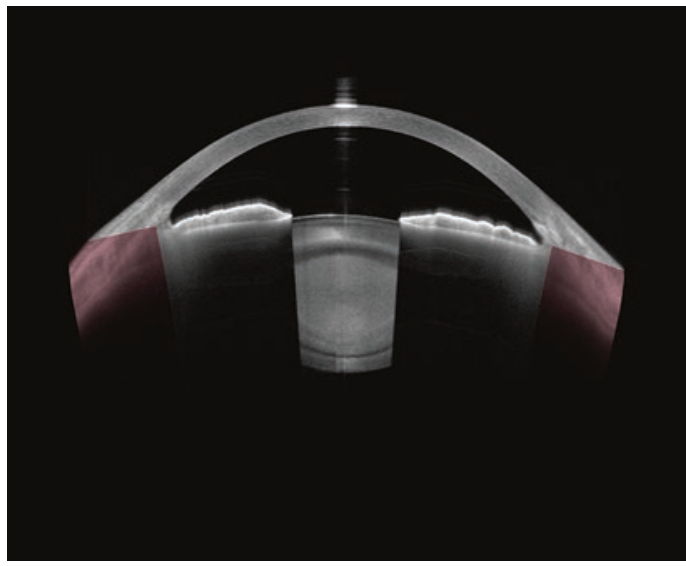

Fig. 13.11 ANTERION Metrics App. Dense cataract OCT image length of $1300 \mathrm{~nm}$ is able to perform corneal, anterior chamber, lens and axial lens measurements (Fig. 13.12). The ability to include all of these parameters and the IOL (intraocular lens) calculation can improve workflow efficiency (Fig. 13.13).

Toric intraocular lens calculation is based on measurements of the anterior surface of the cornea. More recently, estimation algorithms have been introduced for the posterior surface of the cornea, depending on the steep axis of the astigmatism on the anterior surface of the cornea [27-30]. These estimations have resulted in significant improvements in toric IOL power calculations, compared with conventional ones that do not include measurements of the posterior cornea [31]. ANTERION offers a toric IOL calculator, taking the incision location and surgical induced astigmatism (SIA) into account, as well as enabling the surgeon to use the total corneal power as the corneal parameter for the calculation (Fig. 13.14). Further improvements can potentially be achieved, if the post-operative tilt of a toric IOL is predicted using pre-operative

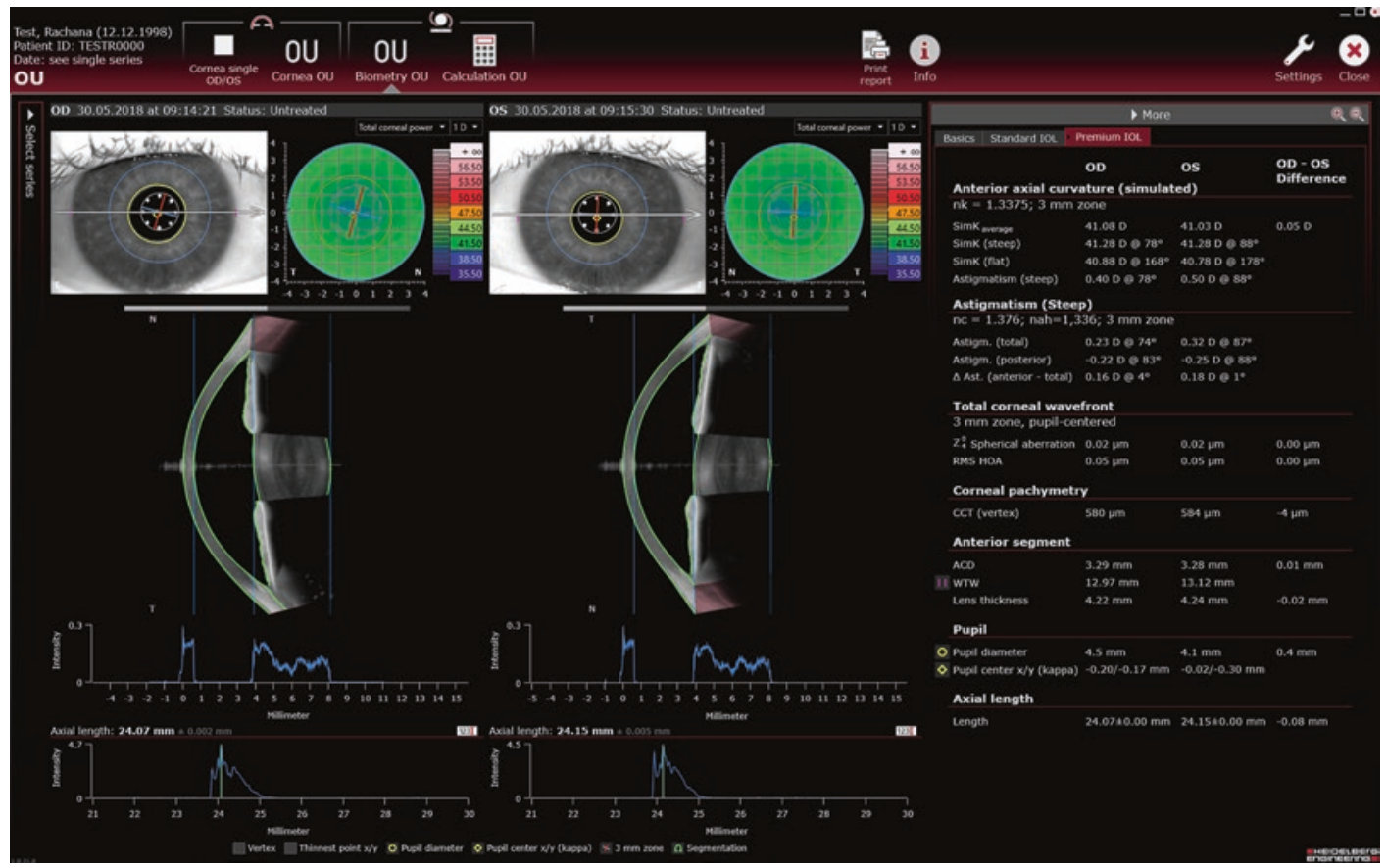

Fig. 13.12 ANTERION Cataract App both eyes (OU) view. Total corneal power maps, anterior segment OCT section image and OCT intensity graph, axial length diagram and anterior segment parameters of a patient with cataract 


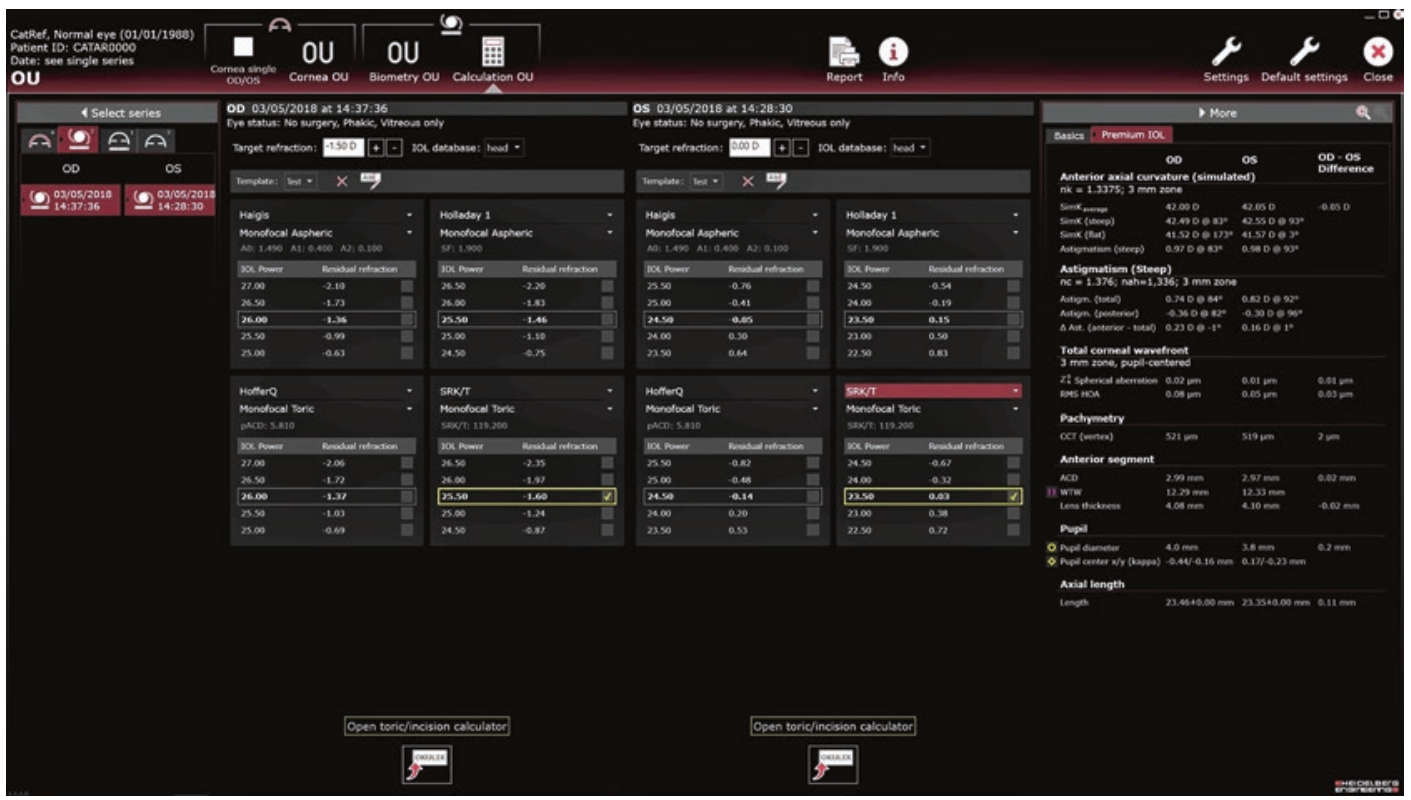

Fig. 13.13 ANTERION Cataract App. Spheric IOL (intraocular lens) calculator

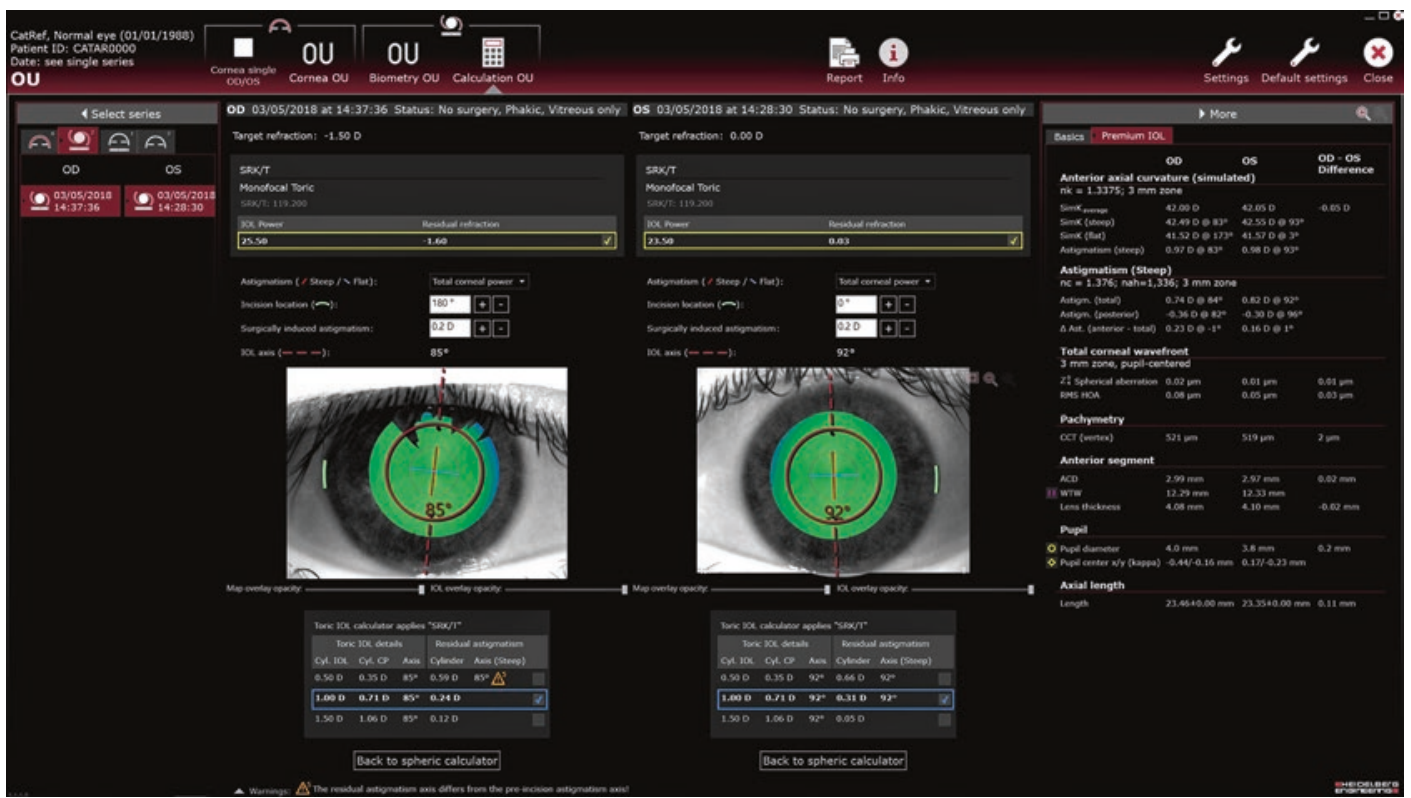

Fig. 13.14 ANTERION Cataract App. Toric IOL calculator

SS-OCT measurements of the crystalline lens [32]. The concept behind this idea is that the post-operative tilt of an IOL has an influence on the post-operative refraction (and even more on higher-order aberrations). This knowledge can be used to adapt toric IOL power calculations in a ray tracing model to improve the post-operative refractive outcome.

Intra-operatively, OCT measurements of aphakic eyes have been shown in some publications 
to lead to better prediction of the post-operative IOL position compared to pre-operative measurements [33, 34]. On the other hand, SS-OCT images can be also used to evaluate and confirm the correct position of the implanted IOL after cataract surgery (Fig. 13.15).

Furthermore, OCT measurements have been shown to be useful for size calculation of posterior chamber phakic lenses, such as the implantable collamer lens [35]. This may help avoid excessive vaulting of such IOLs as well as touching of

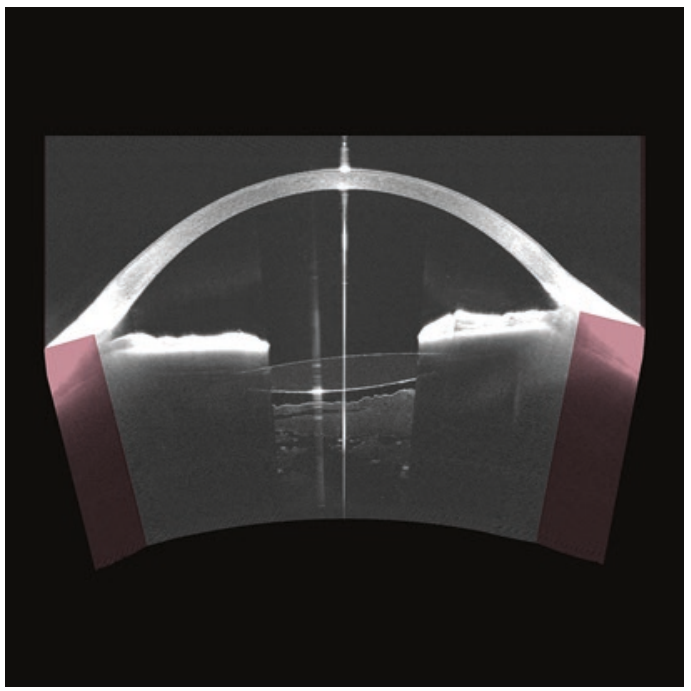

Fig. 13.15 ANTERION Metrics App. Posterior chamber intraocular lens after cataract surgery with anterior vitreous visualization the IOL to the crystalline lens. The post-operative IOL location can be visualized and followed up with high-resolution images (Fig. 13.16).

\subsubsection{SS-OCT and Anterior Chamber Evaluation}

One of the main application areas for SS-OCT is to evaluate the anterior chamber angle [36]. It has been shown that SS-OCT measurements are comparable to gonioscopy, with the additional benefit of better documentation and a non-contact technique [37]. However, it should be mentioned that indentation gonioscopy should not be replaced by OCT.

Due to a large dynamic range and image size, ANTERION images present high scatter in the iris and low scatter in the sclera and lens in one single image, allowing for good visualization of the anterior chamber structures. In addition to conventional anterior chamber angle parameters, such as ACA, SSA, AOD and TISA, lens measurements (lens thickness and lens vault) are also available. Information about the anterior chamber (as depth, volume, ACA distance and spur-to-spur distance) and cornea (central corneal thickness and white-to-white) are displayed as well (Figs. 13.17 and 13.18). This helps in assessing the anterior chamber angle architecture and its changes over time or after treatment.
Fig.13.16 ANTERION Metrics App. Phakic posterior chamber intraocular lens and peripheral patent iridotomy

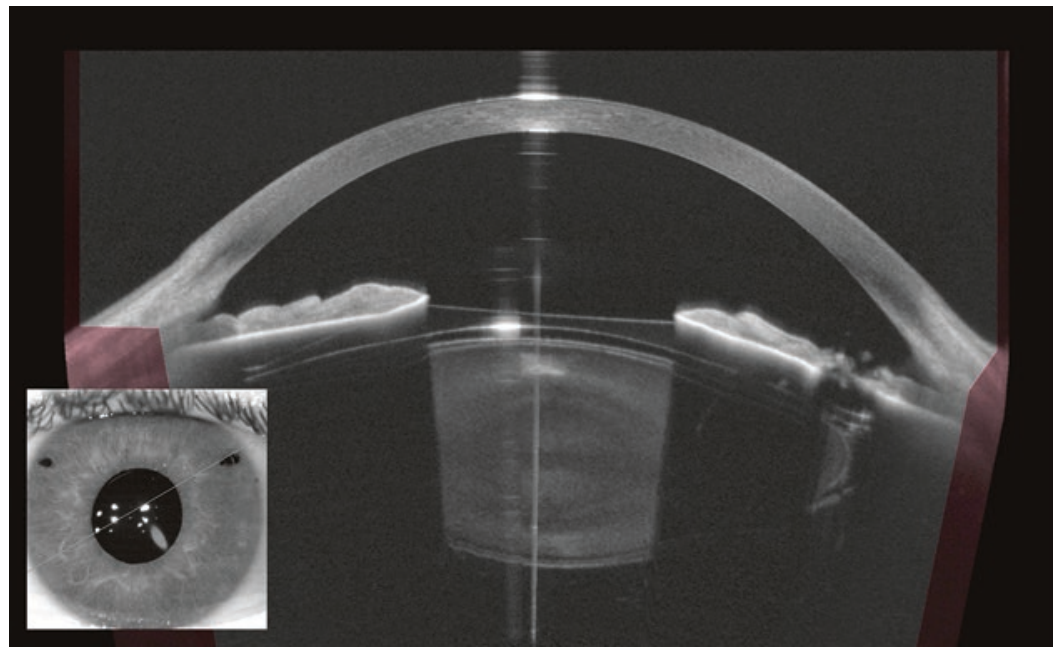




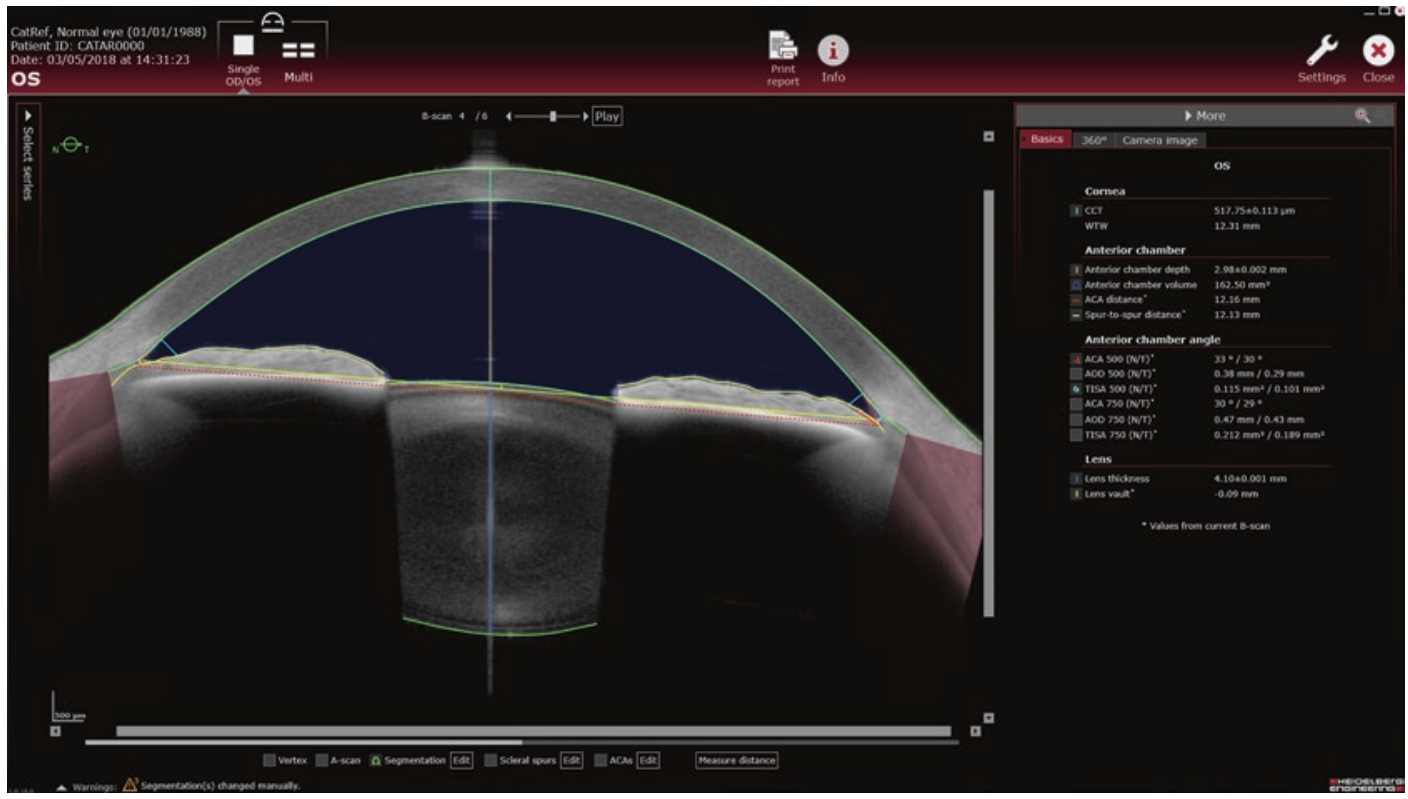

Fig. 13.17 ANTERION Metrics App single view. OCT image and anterior chamber parameters of a healthy patient with open anterior chamber angle

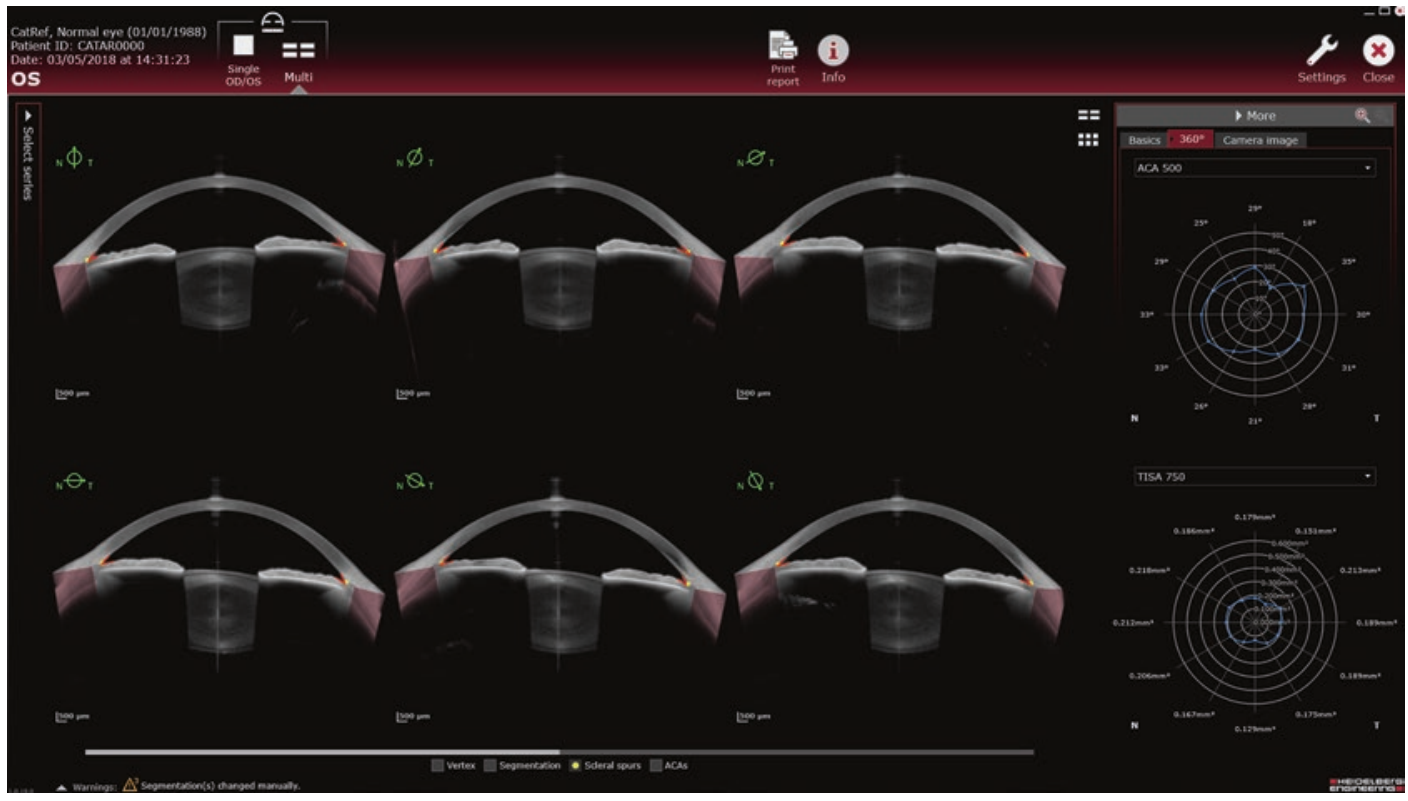

Fig. 13.18 ANTERION Metrics App multiview. OCT images of the whole anterior chamber and $360^{\circ}$ ACA 500 and TISA 750 graph analysis

SS-OCT assessment of the anterior chamber angle is an especially useful measurement technique due to its short measurement time and its non-contact nature. Repeated measurements of the angle can be useful to evaluate diurnal changes [38]. Furthermore, can be used to evaluate the iris and angle configuration before and after laser iridotomy. With high-resolution SS-OCT imaging, 


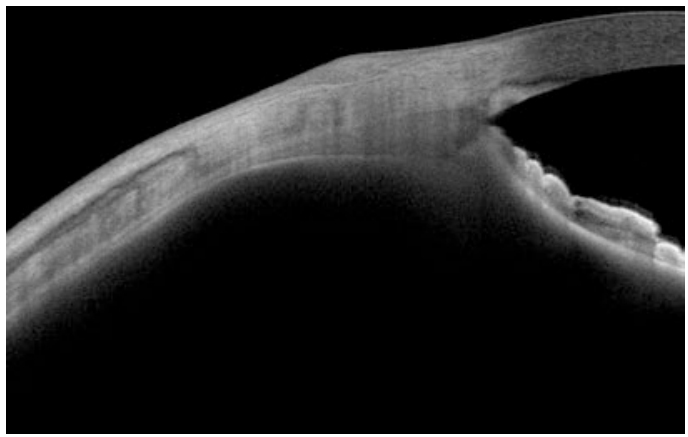

Fig. 13.19 ANTERION Imaging App. Conjunctival nevus with also visualization of the iris, anterior chamber angle, ciliary body and rectus muscle

it is also possible to detect changes of the iris in neovascular glaucoma [39]. SS-OCT imaging offers other potential anterior chamber applications such as flare measurement in the anterior chamber, which has been shown comparable to laser flare meter measurements [40].

\subsubsection{SS-OCT and Anterior Segment Imaging}

There is a variety of other applications for SS-OCT imaging of the anterior segment. The long wavelength enables visualization of the anterior segment along a large image depth, ranging from the anterior surface of the cornea to the posterior surface of the lens. Other ocular structures, such as the sclera, ciliary body and rectus muscles can also be well visualized. The visualization of these structures enables the diagnosis of abnormalities, such as conjunctival nevus (Fig. 13.19). Evaluating the presence and extent of penetration of the cornea and sclera in trauma cases is another important application that is enabled by SS-OCT imaging [41].

\subsection{Summary and Outlook}

The impact and potential applications of anterior segment OCT in clinical practice has been steadily growing. Technological improvements such as acquisition speed and image resolu- tion have made OCT imaging a key part of clinical evaluation, not just for the cornea, but for the whole anterior segment. Multiple scans and precise measurements are very important, allowing for diagnosis and follow-up with high confidence.

Spectral-domain OCT allows for highresolution images of the anterior segment. With these images, the SPECTRALIS Anterior Segment Module provides visualization of the corneal layers in detail, with good histopathological correlation. Some important clinical applications include: LASIK flap evaluation, keratoconus treatment (e.g., corneal rings and crosslinking), Descemet membrane detachments, and corneal transplantations.

ANTERION combines swept-source OCT (SS-OCT) technology and a longer wavelength light source of $1300 \mathrm{~nm}$ to optimize image acquisition of anterior segment structures, with reliable resultant analyses. The combination of a $1300 \mathrm{~nm}$ wavelength light source and SS-OCT technology, allows for minimal sensitivity rolloff along a large dynamic range, resulting in high-contrast images of the entire anterior segment of the eye and the posterior lens. This combination results in detailed visualization and analytics of anterior segment structures using one device. These structures include the cornea, anterior chamber and angle, iris, and lens. ANTERION is also able to measure the axial length of the human eye.

ANTERION can substantially improve the workflow in clinics as it is a real all-in-one solution for anterior segment examination. The cornea examination, eye and anterior segment biometry, IOL calculation and anterior segment imaging can be performed quickly, facilitating the acquisition and optimization of data analyzed by ophthalmologists. The ability to add new features and functionalities reinforces the potential advancements of this technology. The modular design of the ANTERION offers clinicians the ability to tailor the device to their practice needs, with the capability to add features when indicated.

In summary, SS-OCT technology combined with a longer wavelength light source is optimal 
for anterior segment imaging and measurements. It is likely that this combination will replace other technologies in the near future and new application areas will be found.

\section{References}

1. Venkateswaran N, Galor A, Wang J, Karp CL. Optical coherence tomography for ocular surface and corneal diseases: a review. Eye Vis (Lond). 2018;12(5):13.

2. Ang M, Baskaran M, Wekmeister RM, Chua J, Schmidl D, Aranha Dos Santos V, Garhöfer G, Mehta JS, Schmetterer L. Anterior segment optical coherence tomography. Prog Retin Eye Res. 2018;66:132-56.

3. Werkmeister RM, Sapeta S, Schmidl D, Garhöfer G, Schmidinger G, Aranha Dos Santos V, Aschinger GC, Baumgartner I, Pircher N, Schwarzhans F, Pantalon A, Dua H, Schmetterer L. Ultrahigh-resolution OCT imaging of the human cornea. Biomed Opt Express. 2017;8(2):1221-39.

4. Yamazaki N, Kobayashi A, Yokogawa H, Ishibashi Y, Oikawa Y, Tokoro M, Sugiyama K. In vivo imaging of radial keratoneuritis in patients with Acanthamoeba keratitis by anterior-segment optical coherence tomography. Ophthalmology. 2014;121(11):2153-8.

5. Dhaini AR, Abdul Fattah M, El-Oud SM, Awwad ST. Automated detection and classification of corneal haze using optical coherence tomography in patients with keratoconus after cross-linking. Cornea. 2018;37(7):863-9.

6. Yokogawa H, Kobayashi A, Yamazaki N, Sugiyama $\mathrm{K}$. In vivo imaging of coin-shaped lesions in cytomegalovirus corneal endotheliitis by anterior segment optical coherence tomography. Cornea. 2014;33(12):1332-5.

7. Schroder S, Maurer S, Eppig T, Seitz B, Rubly K, Langenbucher A. Comparison of corneal tomography: repeatability, precision, misalignment, mean elevation, and mean pachymetry. Curr Eye Res. 2018;43(6):709-16.

8. Szalai E, Nemeth G, Hassan Z, Modis L Jr. Noncontact evaluation of corneal grafts: swept-source Fourier domain OCT versus high-resolution scheimpflug imaging. Cornea. 2017;36(4):434-9.

9. Gokul A, Vellara HR, Patel DV. Advanced anterior segment imaging in keratoconus: a review. Clin Exp Ophthalmol. 2018;46(2):122-32.

10. Steinberg J, Casagrande MK, Frings A, Katz T, Druchkiv V, Richard G, Linke SJ. Screening for subclinical keratoconus using swept-source Fourier domain anterior segment optical coherence tomography. Cornea. 2015;34(11):1413-9.

11. Han SB, Liu YC, Noriega KM, Mehta JS. Applications of anterior segment optical coherence tomography in cornea and ocular surface diseases. J Ophthalmol. 2016;2016:4971572.
12. Rio-Cristobal A, Martin R. Corneal assessment technologies: current status. Surv Ophthalmol. 2014;59(6):599-614.

13. Li M, Zhao Y, Xiao Q, Yao P, Piao M, Sun L, Zhou $\mathrm{X}$. Demarcation line in the human cornea after surface ablation observed by optical coherence tomography and confocal microscopy. Eye Contact Lens. 2018;44(Suppl 2):19-23.

14. Fukuda R, Usui T, Miyai T, Yamagami S, Amano S. Tear meniscus evaluation by anterior segment swept-source optical coherence tomography. Am J Ophthalmol. 2013;155(4):620-4, 4.e1-2

15. Akiyama R, Usui T, Yamagami S. Diagnosis of dry eye by tear meniscus measurements using anterior segment swept source optical coherence tomography. Cornea. 2015;34(Suppl 11):115-20.

16. Akiyama-Fukuda R, Usui T, Yoshida T, Yamagami $\mathrm{S}$. Evaluation of tear meniscus dynamics using anterior segment swept-source optical coherence tomography after topical solution instillation for dry eye. Cornea. 2016;35(5):654-8.

17. Takezawa Y, Suzuki T, Shiraishi A. Observation of retrocorneal plaques in patients with infectious keratitis using anterior segment optical coherence tomography. Cornea. 2017;36(10):1237-42.

18. Yamaguchi T, Shimizu E, Yagi-Yaguchi Y, Tomida D, Satake Y, Shimazaki J. A novel entity of corneal diseases with irregular posterior corneal surfaces: concept and clinical relevance. Cornea. 2017;36(Suppl 1):53-9.

19. Shimizu E, Yamaguchi T, Tomida D, Yagi-Yaguchi Y, Satake Y, Tsubota K, Shimazaki J. Corneal higherorder aberrations and visual improvement following corneal transplantation in treating herpes simplex keratitis. Am J Ophthalmol. 2017;184:1-10.

20. Mazlin V, Xiao P, Dalimier E, Grieve K, Irsch K, Sahel JA, Fink M, Boccara AC. In vivo high resolution human corneal imaging using full-field optical coherence tomography. Biomed Opt Express. 2018;9(2):557-68.

21. Cai Y, Alio Del Barrio JL, Wilkins MR, Ang M. Serial optical coherence tomography angiography for corneal vascularization. Graefes Arch Clin Exp Ophthalmol. 2017;255(1):135-9.

22. Ang M, Cai Y, MacPhee B, Sim DA, Keane PA, Sng CC, Egan CA, Tufail A, Larkin DF, Wilkins MR. Optical coherence tomography angiography and indocyanine green angiography for corneal vascularisation. Br J Ophthalmol. 2016;100(11):1557-63.

23. Ang M, Sim DA, Keane PA, Sng CC, Egan CA, Tufail A, Wilkins MR. Optical coherence tomography angiography for anterior segment vasculature imaging. Ophthalmology. 2015;122(9):1740-7.

24. de Castro A, Benito A, Manzanera S, Mompeán J, Cañizares B, Martínez D, Marín JM, Grulkowski I, Artal P. Three-dimensional cataract crystalline lens imaging with swept-source optical coherence tomography. Invest Ophthalmol Vis Sci. 2018:59(2):897-903. 
25. Shoji T, Kato N, Ishikawa S, Ibuki H, Yamada N, Kimura I, Shinoda K. In vivo crystalline lens measurements with novel swept-source optical coherent tomography: an investigation on variability of measurement. BMJ Open Ophthalmol. 2017;1(1):e00058.

26. Hirnschall N, Varsits R, Doeller B, Findl O. Enhanced penetration for axial length measurement of eyes with dense cataracts using swept source optical coherence tomography: a consecutive observational study. Ophthalmol Ther. 2018;7(1):119-24.

27. Koch DD, Jenkins RB, Weikert MP, Yeu E, Wang L. Correcting astigmatism with toric intraocular lenses: effect of posterior corneal astigmatism. J Cataract Refract Surg. 2013;39(12):1803-9.

28. Koch DD, Ali SF, Weikert MP, Shirayama M, Jenkins R, Wang L. Contribution of posterior corneal astigmatism to total corneal astigmatism. J Cataract Refract Surg. 2012;38(12):2080-7.

29. Abulafia A, Hill WE, Franchina M, Barrett GD. Comparison of methods to predict residual astigmatism after intraocular lens implantation. J Refract Surg. 2015;31(10):699-707.

30. Abulafia A, Koch DD, Wang L, Hill WE, Assia EI, Franchina M, Barrett GD. New regression formula for toric intraocular lens calculations. J Cataract Refract Surg. 2016;42(5):663-71.

31. Hoffmann PC, Abraham M, Hirnschall N, Findl O. Prediction of residual astigmatism after cataract surgery using swept source Fourier domain optical coherence tomography. Curr Eye Res. 2014;39(12):1178-86.

32. Hirnschall N, Buehren T, Bajramovic F, Trost M, Teuber T, Findl O. Prediction of postoperative intraocular lens tilt using swept-source optical coherence tomography. J Cataract Refract Surg. 2017;43(6):732-6.

33. Hirnschall N, Amir-Asgari S, Maedel S, Findl O. Predicting the postoperative intraocular lens position using continuous intraoperative optical coherence tomography measurements. Invest Ophthalmol Vis Sci. 2013;54(8):5196-203.
34. Hirnschall N, Norrby S, Weber M, Maedel S, AmirAsgari S, Findl O. Using continuous intraoperative optical coherence tomography measurements of the aphakic eye for intraocular lens power calculation. $\mathrm{Br}$ J Ophthalmol. 2015;99(1):7-10.

35. Nakamura T, Isogai N, Kojima T, Yoshida Y, Sugiyama Y. Implantable collamer lens sizing method based on swept-source anterior segment optical coherence tomography. Am J Ophthalmol. 2018;187:99-107.

36. Romkens HC, Beckers HJ, Schouten JS, Berendschot TT, Webers CA. Reference values for anterior chamber morphometrics with swept-source optical coherence tomography in a Caucasian population. Clin Ophthalmol. 2018;12:411-7.

37. Rigi M, Bell NP, Lee DA, Baker LA, Chuang AZ, Nguyen D, Minnal VR, Feldman RM, Blieden LS. Agreement between gonioscopic examination and swept source Fourier domain anterior segment optical coherence tomography imaging. J Ophthalmol. 2016;2016:1727039.

38. Xu BY, Penteado RC, Weinreb RN. Diurnal variation of optical coherence tomography measurements of static and dynamic anterior segment parameters. J Glaucoma. 2018;27(1):16-21.

39. Nakakura S, Kobayashi Y, Matsuya K, Terao E, Kiuchi Y. Iris thickness and severity of neovascular glaucoma determined using swept-source anteriorsegment optical coherence tomography. J Glaucoma. 2018;27(5):415-20.

40. Invernizzi A, Marchi S, Aldigeri R, Mastrofilippo V, Viscogliosi F, Soldani A, Adani C, Garoli E, Viola F, Fontana L, McCluskey P, Cimino L. Objective quantification of anterior chamber inflammation: measuring cells and flare by anterior segment optical coherence tomography. Ophthalmology. 2017;124(11):1670-7.

41. Akil H, Minasyan L, Francis BA, Chopra V. Utility of anterior segment swept-source optical coherence tomography for imaging eyes with antecedent ocular trauma. Am J Ophthalmol Case Rep. 2016;3:18-21.

Open Access This chapter is licensed under the terms of the Creative Commons Attribution 4.0 International License (http://creativecommons.org/licenses/by/4.0/), which permits use, sharing, adaptation, distribution and reproduction in any medium or format, as long as you give appropriate credit to the original author(s) and the source, provide a link to the Creative Commons license and indicate if changes were made.

The images or other third party material in this chapter are included in the chapter's Creative Commons license, unless indicated otherwise in a credit line to the material. If material is not included in the chapter's Creative Commons license and your intended use is not permitted by statutory regulation or exceeds the permitted use, you will need to obtain permission directly from the copyright holder.

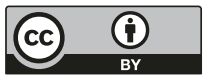

